\title{
Regenerated cellulose from $N$-methylmorpholine $N$-oxide solutions as a coating agent for paper materials
}

\author{
Marta Krysztof • Konrad Olejnik (1) P Piotr Kulpinski • Anna Stanislawska • \\ Svitlana Khadzhynova
}

Received: 11 November 2017 / Accepted: 17 April 2018/Published online: 21 April 2018

(C) The Author(s) 2018

\begin{abstract}
The objective of the presented research was to determine the influence of cellulose coating, obtained from the cellulose solution in $N$-Methylmorpholine $N$-oxide (NMMO), on the structural and mechanical properties of paper. The effect of heating time of paper samples coated with cellulose dissolved in NMMO was also investigated. Depending on the heating time of the coating, a continuous or porous layer was obtained. Coating without any heating stage yielded a continuous cellulose layer of hydrophobic properties (higher contact angle in comparison to base
\end{abstract}

paper), and paper of higher smoothness and increased tear resistance. Analysis of the paper samples showed that cellulose coating not only changed the surface properties of paper, but also significantly improved paper strength properties, such as the tensile index, elongation, bursting strength index and double folds number. Despite the process' limitations (e.g. necessity of removing the NMMO), this method can be considered as a novel approach for paper property modification.

M. Krysztof · K. Olejnik ( $\varangle) \cdot$ A. Stanislawska ·

S. Khadzhynova

Institute of Papermaking and Printing, Faculty of

Management and Production Engineering, Lodz

University of Technology, Wolczanska 223, 90-924 Lodz,

Poland

e-mail: konrad.olejnik@p.lodz.pl

P. Kulpinski

Department of Man-Made Fibers, Lodz University of

Technology, Zeromskiego 116, 90-924 Lodz, Poland 


\section{Graphical Abstract}

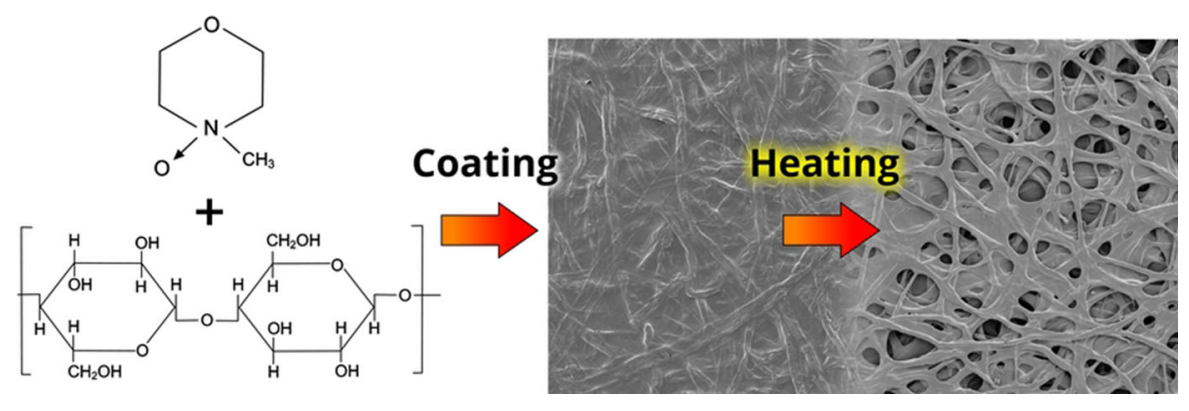

Keywords Paper coating - Regenerated cellulose · $\mathrm{N}$-Methylmorpholine $\mathrm{N}$-oxide · NMMO $\cdot$ Cellulosic coating $\cdot$ Mechanical properties $\cdot$ Surface modification

\section{Introduction}

The coating of paper materials is one of the most commonly applied methods for altering their surface properties. Depending on the coating suspension composition, it is possible to improve paper strength, adhesive, printing, barrier and antibacterial properties, control the coefficient of friction and fire retardancy, modify thermal and electrical conductivity, and also to enhance the many different properties of other endproducts (Choi et al. 2002; Tracton 2007; Andersson 2008; Gardner et al. 2008; Liu et al. 2011; Salas et al. 2014; Mngomezulu and John 2017). A lot of substances used for coating purposes are of synthetic origin (e.g. PET, PVC, PP, waxes, latexes). Such compounds-apart from their advantages, i.e. good barrier properties, high strength, low price, easy application-have many drawbacks, especially with regard to their negative environmental impact and recycling difficulties (Andersson 2008). This is one of the reasons for research aiming at reducing the content of synthetic polymers or replacing them by natural polymers (Khwaldia et al. 2010). Nowadays, such reports and their results can be found in the literature discussing the possible application of more environmentally friendly biopolymers, such as whey proteins, chitosan (Gällstedt et al. 2005), starch (Garcia et al. 1999) and alginates (Rhim et al. 2006). Another, but equally important, reason to conduct such research is to seek out truly environmentally friendly substances, which would make it possible to obtain new paper material properties, while at the same time developing novel composite or hybrid biomaterials (Salas et al. 2014; Hubbe et al. 2017). Different forms of cellulose, in particular, microfibrillated, microcrystalline cellulose and nanocellulose, are currently among the substances widely studied to meet these objectives (Lavoine et al. 2014; Nakagaito and Yano 2005). Numerous scientific publications (Zimmermann et al. 2005, 2010; Henriksson et al. 2008; Hansen and Plackett 2008; Fukuzumi et al. 2009; Tingaut et al. 2011; Lavoine et al. 2012; Dufresne 2012, 2013; Siró and Plackett 2010; Savadekar et al. 2015; Spence et al. 2010; Kangas et al. 2014; Mngomezulu and John 2017) indicate the possible application of these forms of cellulose in the production of new, environmentally friendly materials. Those researchers determined, among other things, that the addition of micro- and nanocellulose significantly influenced the material structure. Therefore, it is possible to modify the mechanical and barrier properties of fibrous materials. For example, Ferrer et al. (2012) and Fall et al. (2014) reported that nanocellulose-based materials had the following major features: high specific surface area, high density $\left(1100-1560 \mathrm{~kg} / \mathrm{m}^{3}\right)$ and high strain at break (up to $10 \%$ ). Additionally, the elastic modulus of cellulose nanocrystals could be as high as $143 \mathrm{GPa}$ (Šturcová et al. 2005). From a practical viewpoint, the hydrophilicity of microcrystalline cellulose and nanocellulose is a significant advantage, as it enables them to be applied in water-based systems and/or in mixtures with other hydrophilic substances. The presence of the - $\mathrm{OH}$ groups in the cellulose macromolecule may contribute to the ordered structures of the cellulose chains. As a result, these structures possess hydrogen bonding potential and, thus, they may be combined with other polymer materials (Gardner et al. 2008; Erdman et al. 2016). This makes 
it possible to produce new, biodegradable composites of exclusive characteristics, e.g. barrier properties (Hubbe et al. 2017) or even substrates for printed electronic products (Lee et al. 2009; Peresin and Rojas 2014). Moreover, using the same polymer for the surface modification as that present in the natural fibers may result in strong adhesion between the coating layer and the base paper. Despite being a hydrophilic and hydrogen-bonded substance, cellulose neither dissolves in water nor in many popular volatile polar and non-polar organic solvents (e.g. ethanol, methanol). The lack of simple dissolving systems is a direct outcome of the complex chemical structure of cellulose. The cellulose macromolecule contains a high number of hydroxyl groups prone to the formation of a strong and highly structured intra- and intermolecular hydrogen-bonding network, which resists water and most organic solvents. Therefore, cellulose solubility depends on the ability of the solvent to break these interactions (Yamane et al. 2006; Lindman et al. 2010; Medronho and Lindman 2014, 2015). Cellulose contains multiple hydroxyl groups on the glucopyranose ring and, therefore, its insolubility in water is rather unexpected. It might be explained-according to recent investigations-by its amphiphilic nature. This means that the glucopyranose ring exhibits both a hydrophobic and hydrophilic character. The axial direction of the ring is hydrophobic as a result of the location of $\mathrm{C}-\mathrm{H}$ bonds along the axial position. Hydrogen atoms connected directly to the carbons do not contribute to the hydrogen bonding. According to simulations carried out by Mazeau (2011), the surface energy of the layer of $\mathrm{C}-\mathrm{H}$ moieties is the lowest and, as a consequence, the attachment energy, which is mainly of van der Waals type, is less favourable than that of other surfaces of the cellulose. Hydrophobic interactions obviously limit cellulose solubility in polar solvents. The equatorial direction of the ring is hydrophilic since the hydroxyl groups-responsible for hydrogen bonding - are located along this direction. Hence, cellulose macromolecules exhibit differences in polarity (Yamane et al. 2006; Medronho et al. 2012). The situation is more complex due to the presence of various crystalline phases in native cellulose. There are three principal phases: type I $\alpha$ (triclinic), I $\beta$ (monoclinic) and type II (Biermann et al. 2001). Affinity of all these phases to water and to many organic solvents has not yet been fully investigated. Some authors also link cellulose insolubility with its crystallinity (Cao et al. 1994; Medronho et al. 2012). The chemical structure and properties of cellulose may suggest that amphiphilic solvents would be the most suitable for cellulose dissolution. Ionic liquids (Kosan et al. 2008) and some organic solvents exhibit such properties (Kalashnikova et al. 2012; Lindman et al. 2010; Medronho and Lindman 2014). It should be emphasised that, even though many different systems that dissolve cellulose are described in the scientific papers, not all of them are amphiphilic (Alves et al. 2016). NMethylmorpholine $\mathrm{N}$-oxide (NMMO) is an example of such a system. The mechanism of cellulose dissolution in NMMO systems has been described in the literature (Medronho and Lindman 2014). The proposed mechanism, however, does not fully explain the occurring changes. For instance, it does not include the impact of water molecules, which are crucial for the NMMO cellulose dissolving system. Experimental practice indicates (Lindman et al. 2010) that lack of water results in cellulose insolubility in NMMO. Conversely, at too high water content, cellulose would not dissolve either. This emphasises the water-sensitivity of the process. Nonetheless, among different cellulose solvents, NMMO seems to be the most interesting and promising from the viewpoint of paper material modifications. This solvent has been the subject matter of research for many years (Kulpinski 2007; Kulpinski et al. 2011; Erdman et al. 2016). Nowadays, it is applied on an industrial scale for the production of cellulose fibers, known under the brand name of Lyocell or Tencel. Low toxicity is one of the most important advantages of this solvent. The possibility to obtain cellulose solutions in a wide range of concentrations, from less than $1 \%$ to approximately $28 \%$ by weight, is another advantage. No less important is the fact that - in the case of NMMO- the cellulose solidification process is carried out in water baths. So far, methods for modifying paper with the application of NMMO have been scarcely studied. Johnson (1969) patented a method in which only NMMO (without cellulose) was used for paper mechanical property improvement. In another patent, Melville et al. (2014) applied a mixture of NMMO, water and fluorinated polymer particle suspension to modify paper surface so that its abrasion resistance would be increased and, simultaneously, its friction coefficient decreased. Paper with an applied wet layer was heated at a temperature of $100{ }^{\circ} \mathrm{C}$ to ensure good 
adhesion to paper fibers. Afterwards, NMMO was washed out from the paper with water. The NMMO cellulose solution, containing dispersed kaolinite, was applied in research conducted by Se Young Yoon (2007). Such a system was used to form paper-based composite materials of improved strength properties. In the literature, one may find information into the properties of membranes, made of cellulose dissolved in NMMO, which afterwards were used to filtrate, e.g. gases (Jie et al. 2005). The above-mentioned patents and scientific articles did not include the experiments presented in this publication, i.e. in neither was the cellulose solution in NMMO used to coat the surface of paper. The method applied in this research is safe because the solvent is both non-toxic and nonflammable. Furthermore, NMMO is considered environmentally friendly. It can be reused with a percent recovery of $98 \%$ or even higher (Rosenau et al. 2001; Chen et al. 2015). This technology also significantly reduces problems related to post-consumer material recycling.

The objective of the research was to determine the interactions between the NMMO cellulose solution and paper, whose surface had been coated by that solution. In particular, the impact on the structural and strength properties of paper was investigated. This study is part of a larger research project on fibrous material modification by means of a surface treatment operation, namely by coating the substrate with the solution containing cellulose dissolved in NMMO.

\section{Materials and methods}

\section{Cellulose solution preparation}

Bleached beech kraft pulp of Degree of Polymerisation (DP) of 655 and $\alpha$-cellulose content of $92.3 \%$ was used for the cellulose solution preparation. This type of pulp was selected because of its relatively low degree of polymerisation and short fibers that enabled the dissolution of such cellulose under mild conditions. According to the authors' experience, it is very difficult to run a coating operation using solutions of higher than $5 \%$ cellulose concentration due to high solution viscosity, resulting in runnability problems. Conversely, the application of significantly lower concentration solutions results in insufficient deposition of cellulose on the base paper. Therefore, for the coating solutions used here, cellulose content of $3 \%$ was selected as the most effective from a practical point of view. The cellulose solutions were obtained in a high efficiency laboratory-scale IKAVISC kneader type MKD 0.6-H60. The mixture of 50/50 water and NMMO with an addition of $3 \%$ of cellulosic material (based on NMMO weight) was heated at a temperature of $95^{\circ} \mathrm{C}$ and under low pressure (of about $6.7 \mathrm{kPa}$ ), and the excess of water was removed from the system. The process was continued until a homogeneous and transparent cellulose solution in NMMO was obtained.

\section{Base paper preparation}

Commercial, bleached softwood pine kraft pulp (BSK) was used to prepare laboratory handsheets. Pulp parameters were as follows: initial moisture content $93.78 \%$; $\alpha$-cellulose content $86.6 \%$; DP 1081; Schopper-Riegler value SR-12. Pulp samples were prepared according to standard ISO 5263-1:2004. Unbeaten pulp was examined and laboratory sheets of $70 \mathrm{~g} / \mathrm{m}^{2}$ were formed in Rapid-Köthen apparatus according to standard ISO 5259-2:2001. The obtained laboratory sheets were used as base paper for a subsequent coating.

Unbeaten pulp was used in order to eliminate the influence of the beating process on the paper mechanical properties. Consequently, it was possible to evaluate the full development of strength properties, resulting only from the applied modifications.

\section{Coating}

The application of cellulose-NMMO solution on the paper surface was conducted using the standard coating process. This operation was carried out with the use of an automatic coater ('Control Coater') of IPP/TUL, Poland, at the speed of $16 \mathrm{~cm} / \mathrm{s}$ and with the use of a standard Mayer rod No. 3 (K-bar), which gave a wet film thickness of $24 \mu \mathrm{m}$ and, hence, a dry coating thickness of about $0.8 \mu \mathrm{m}$. Prior to the coating process, the cellulose solutions were melted and kept at a temperature of $80 \pm 2{ }^{\circ} \mathrm{C}$. Solidification of the coating occurred as a result of washing out the solvent (NMMO) and-afterwards-drying the coated papers. 
Post-treatment

Two post-treatment methods were employed. In the first one, marked as $\mathrm{NH}$ (No Heating), the solvent was washed out immediately after the coating application. In the second method, marked as HA (Heating Applied), before the washing out operation, coated papers were subjected to heating at a temperature of $80 \pm 2{ }^{\circ} \mathrm{C}$ for a time period of $5,10,20,40$ or $60 \mathrm{~min}$. The applied procedures are shown in Fig. 1.

Heating stages were added in order to keep the cellulose solution in a liquid state to observe possible effects related to the further interactions between paper and NMMO. In particular, it was expected that cellulose from the solution would migrate in the presence of NMMO, and that the solvent itself could also interact with cellulosic fibers.

The samples of coated paper were exposed to heat treatment in a KBC-32 drier of WAMED, Poland. NMMO removal from the cellulose coating was carried out by means of immersing a sample of coated paper in a water bath at a temperature of $37^{\circ} \mathrm{C} \pm 2{ }^{\circ} \mathrm{C}$ for $120 \mathrm{~s}$.

The duration and temperature of the washing bath was selected based on the conducted experiments. According to the study, under the chosen conditions, it was possible to remove all NMMO in a relatively short time and to obtain reproducible sample properties.
Structural and mechanical properties testing

Paper samples were conditioned according to ISO 187:1990 standard. All properties were determined in accordance with adequate ISO standards:

- Thickness and apparent density (ISO 534:2005)

- Tensile index and elongation (ISO 1924-2:2008)

- Elmendorf tear resistance (ISO 1974:1990)

- Bendtsen surface roughness (ISO 8791-2:1990)

- Bendtsen air permeance (ISO 5636-3:1992)

- Folding endurance (Schopper device-ISO 5626:1993)

- $\quad$ Bursting strength (ISO 2758:2001)

PG-X Goniometer of Testing Machines Inc. was used for contact angle measurements. The tests were carried out according to TAPPI T 458 standard method.

\section{SEM analysis}

The observation of the paper surface was performed with the use of Scanning Electron Microscope (SEM) VEGA3-SBU. The samples for SEM examination were gold- and palladium-coated using 'Mini' Sputter Coater/Glow Discharge System SC7620.

\section{Results and discussion}

The influence of cellulosic coating on the properties of paper products was studied. Additionally, the effect of the coating post-treatment (heating), carried out before the solvent washing-out operation, was investigated.
Fig. 1 Diagram of the research

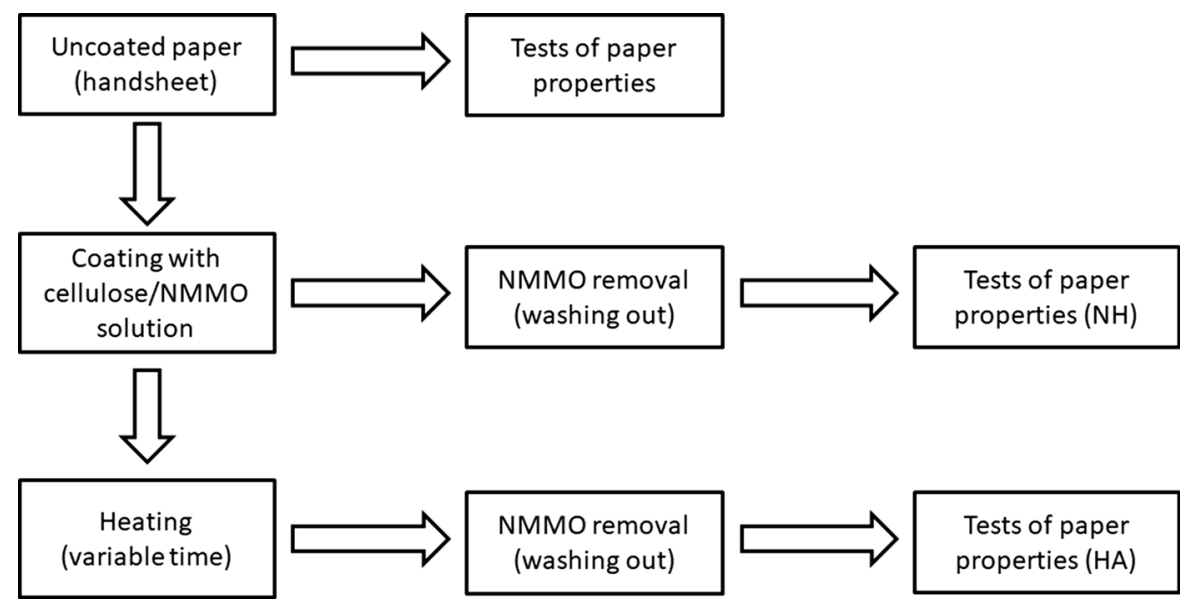


The most important structural and mechanical parameters of all paper samples were determined. The results are presented in Table 1, and also shown in Figs. 2, 3, 4, 5, 6, 7, 8 and 9 .

The basic statistical analysis is presented as a coefficient of variation (given in Table 1) and as error bars, based on standard deviation values (given in figures).

Structural and surface properties

The microscopic observations of the surface of paper samples constituted the first stage of the research. Figure 2 presents: (a) surface of reference paper without coating, (b) surface coated with cellulose dissolved in NMMO, where solvent was removed immediately after a coating operation, (c) surface with coating, where solvent was removed after $10 \mathrm{~min}$ of heat treatment of the coated paper, (d) coated paper surface, where solvent was removed after $40 \mathrm{~min}$ of heat treatment. The presented pictures show that, depending on the applied methodology of modifying a surface by means of the same kind of cellulose solution, it is possible to obtain different coating structures. If the solvent is removed immediately after coating, a continuous coating layer is obtained (Fig. 2b).

When the heat treatment was applied, the continuous layer disappeared (Fig. 2c, d). This effect suggests that the cellulose solution penetrated the structure of the material when the samples were heated. As a result, not only the surface but also the structure of paper was modified. Based on the property measurements and SEM images it could be concluded that, as heat treatment time was extended, the degree of penetration of the paper structure by the cellulose solution increased. Therefore, modification not only of the paper surface, but also of the entire structure of the paper was possible. The results presented below show to what extent the modifications influence the most important properties of paper. The surface roughness values are shown in Fig. 3. The lowest roughness level was found for paper with a continuous regenerated cellulose layer ( $\mathrm{NH}$-without further heating). When heat treatment was applied, roughness increased quickly up to the value comparable with that for uncoated paper. For the longer heat treatment times (over $20 \mathrm{~min}$ ), a certain decline in the roughness of the surface was observed. This decrease might be explained by possible partial swelling and/or

Table 1 Structural and mechanical properties of investigated papers (COV, \%-coefficient of Variation is given inside the parentheses)

\begin{tabular}{|c|c|c|c|c|c|c|c|c|}
\hline $\begin{array}{l}\text { Heat } \\
\text { treatment } \\
\text { time (min) }\end{array}$ & $\begin{array}{l}\text { Apparent } \\
\text { density } \\
\left(\mathrm{g} / \mathrm{cm}^{3}\right)\end{array}$ & $\begin{array}{l}\text { Surface } \\
\text { roughness } \\
(\mathrm{ml} / \mathrm{min})\end{array}$ & $\begin{array}{l}\text { Tensile } \\
\text { index } \\
(\mathrm{N} \mathrm{m} / \mathrm{g})\end{array}$ & $\begin{array}{l}\text { Elongation } \\
(\%)\end{array}$ & $\begin{array}{l}\text { Double } \\
\text { folds } \\
\text { number }\end{array}$ & $\begin{array}{l}\text { Tear } \\
\text { resistance } \\
\text { index } \\
\left(\mathrm{mN} \mathrm{m}^{2} / \mathrm{g}\right)\end{array}$ & $\begin{array}{l}\text { Bursting strength } \\
\text { index }\left(\mathrm{kPa} \mathrm{m}^{2} / \mathrm{g}\right)\end{array}$ & $\begin{array}{l}\text { Air } \\
\text { permeance } \\
(\mathrm{ml} / \mathrm{min})\end{array}$ \\
\hline 0 & $\begin{array}{l}0.555 \\
(2.66 \%)\end{array}$ & $\begin{array}{l}289 \\
(9.9 \%)\end{array}$ & $\begin{array}{l}23.81 \\
(3.21 \%)\end{array}$ & $\begin{array}{l}3.50 \\
(8.72 \%)\end{array}$ & $\begin{array}{l}37 \\
(7.3 \%)\end{array}$ & $\begin{array}{l}8.80 \\
(4.58 \%)\end{array}$ & $\begin{array}{l}0.80 \\
(5.32 \%)\end{array}$ & $\begin{array}{l}181 \\
(9.3 \%)\end{array}$ \\
\hline 5 & $\begin{array}{l}0.593 \\
(1.03 \%)\end{array}$ & $\begin{array}{l}605 \\
(9.2 \%)\end{array}$ & $\begin{array}{l}61.28 \\
(6.73 \%)\end{array}$ & $\begin{array}{l}4.96 \\
(9.82 \%)\end{array}$ & $\begin{array}{l}1527 \\
(8.1 \%)\end{array}$ & $\begin{array}{l}5.94 \\
(5.93 \%)\end{array}$ & $\begin{array}{l}4.45 \\
(6.41 \%)\end{array}$ & $\begin{array}{l}4900 \\
(4.6 \%)\end{array}$ \\
\hline 10 & $\begin{array}{l}0.594 \\
(1.09 \%)\end{array}$ & $\begin{array}{l}623 \\
(9.1 \%)\end{array}$ & $\begin{array}{l}61.09 \\
(5.09 \%)\end{array}$ & $\begin{array}{l}5.48 \\
(3.12 \%)\end{array}$ & $\begin{array}{l}1228 \\
(9.0 \%)\end{array}$ & $\begin{array}{l}5.80 \\
(4.32 \%)\end{array}$ & $\begin{array}{l}6.22 \\
(6.29 \%)\end{array}$ & $\begin{array}{l}4980 \\
(2.9 \%)\end{array}$ \\
\hline 20 & $\begin{array}{l}0.595 \\
(1.72 \%)\end{array}$ & $\begin{array}{l}634 \\
(8.6 \%)\end{array}$ & $\begin{array}{l}59.77 \\
(4.17 \%)\end{array}$ & $\begin{array}{l}5.76 \\
(8.83 \%)\end{array}$ & $\begin{array}{l}1176 \\
(4.4 \%)\end{array}$ & $\begin{array}{l}3.34 \\
(5.0 \%)\end{array}$ & $\begin{array}{l}4.65 \\
(4.90 \%)\end{array}$ & $\begin{array}{l}>5000 \\
(3.3 \%)\end{array}$ \\
\hline 40 & $\begin{array}{l}0.599 \\
(2.41 \%)\end{array}$ & $\begin{array}{l}587 \\
(8.5 \%)\end{array}$ & $\begin{array}{l}64.47 \\
(3.91 \%)\end{array}$ & $\begin{array}{l}5.48 \\
(9.03 \%)\end{array}$ & $\begin{array}{l}1248 \\
(8.1 \%)\end{array}$ & $\begin{array}{l}2.07 \\
(3.68 \%)\end{array}$ & $\begin{array}{l}4.83 \\
(5.19 \%)\end{array}$ & $\begin{array}{l}>5000 \\
(2.7 \%)\end{array}$ \\
\hline 60 & $\begin{array}{l}0.617 \\
(2.59 \%)\end{array}$ & $\begin{array}{l}563 \\
(8.7 \%)\end{array}$ & $\begin{array}{l}58.93 \\
(4.21 \%)\end{array}$ & $\begin{array}{l}4.57 \\
(8.12 \%)\end{array}$ & $\begin{array}{l}1251 \\
(6.4 \%)\end{array}$ & $\begin{array}{l}2.05 \\
(4.12 \%)\end{array}$ & $\begin{array}{l}5.28 \\
(6.28 \%)\end{array}$ & $\begin{array}{l}>5000 \\
(3.1 \%)\end{array}$ \\
\hline $\begin{array}{l}\text { Uncoated } \\
\text { (reference) } \\
\text { paper }\end{array}$ & $\begin{array}{l}0.521 \\
(3.13 \%)\end{array}$ & $\begin{array}{l}611 \\
(5.4 \%)\end{array}$ & $\begin{array}{l}20.21 \\
(3.52 \%)\end{array}$ & $\begin{array}{l}1.86 \\
(8.33 \%)\end{array}$ & $\begin{array}{l}7 \\
(7.31 \%)\end{array}$ & $\begin{array}{l}7.14 \\
(6.18 \%)\end{array}$ & $\begin{array}{l}0.79 \\
(4.78 \%)\end{array}$ & $\begin{array}{l}4500 \\
(10.4 \%)\end{array}$ \\
\hline
\end{tabular}


Fig. 2 Comparison of the surface of laboratory paper samples made from BSK pine pulp a uncoated (reference sample), b coated $(\mathrm{NH})$, c coated (HA) $10 \mathrm{~min}$ of heat treatment, d coated (HA) — 40 min of heat treatment
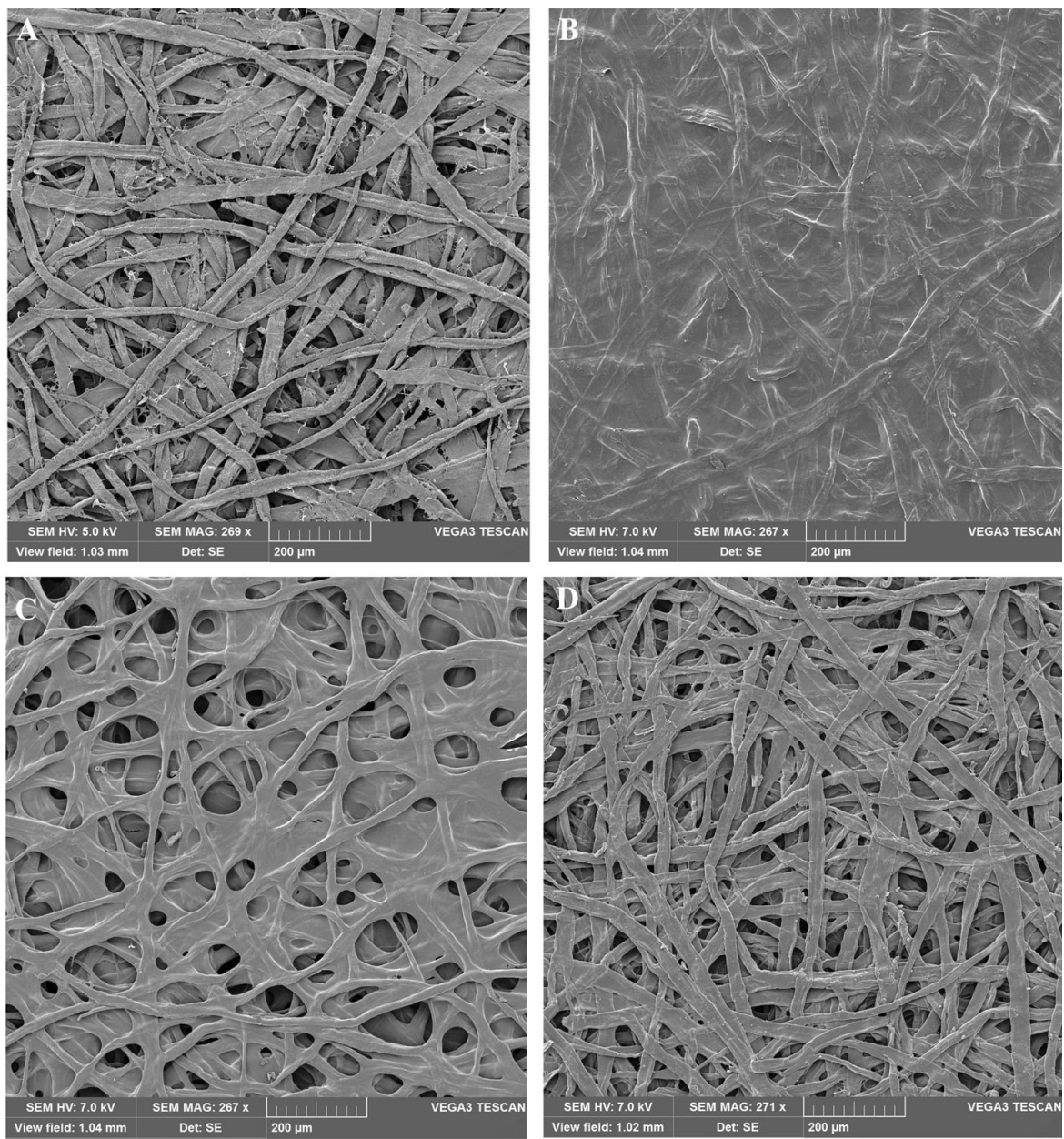

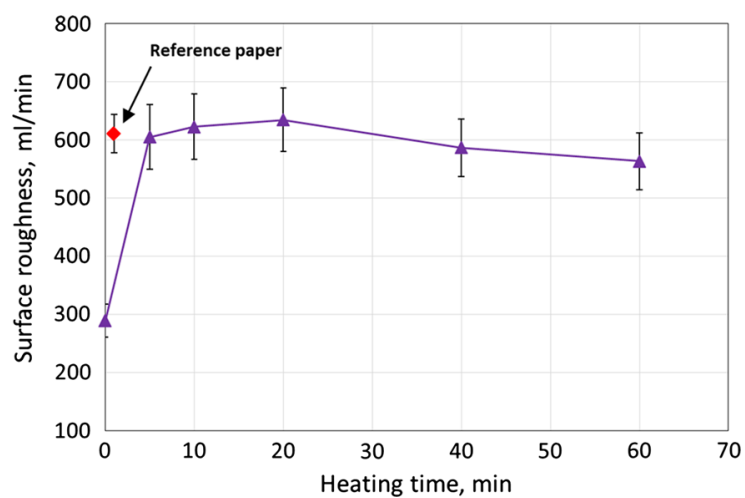

Fig. 3 Effect of heat treatment time on the surface roughness of coated papers (the value for base paper is given as a reference)

dissolution of the base paper cellulose by the concentrated NMMO solution.

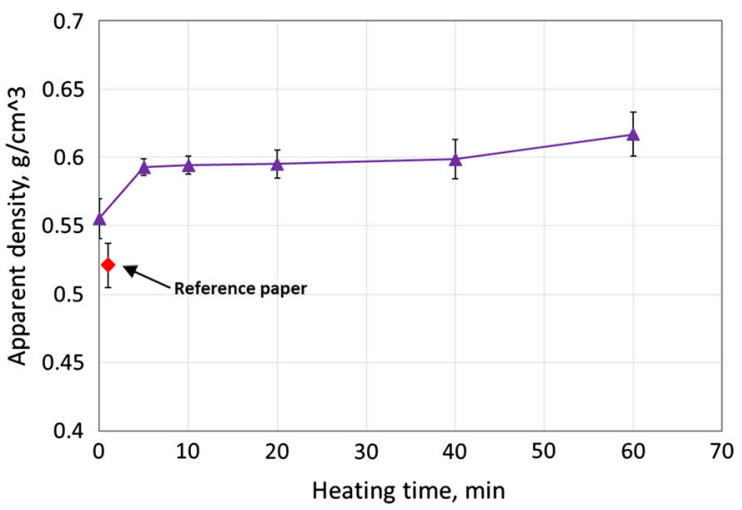

Fig. 4 Effect of heat treatment time on the apparent density of coated papers (the value for base paper is given as a reference)

In Fig. 4, changes in the apparent density of studied samples of paper depending on the duration of heat treatment of the coating are presented. Time equal to 
Fig. 5 Close view of the surface of the reference paper (left) and the coated paper after $10 \mathrm{~min}$ of heat treatment (right)
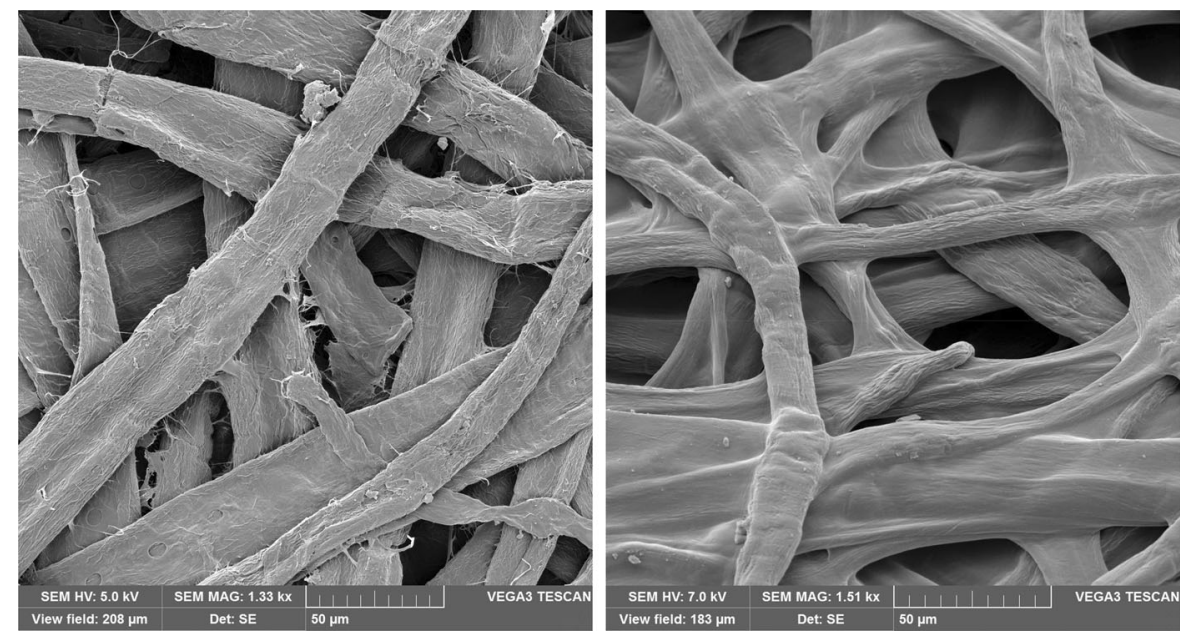

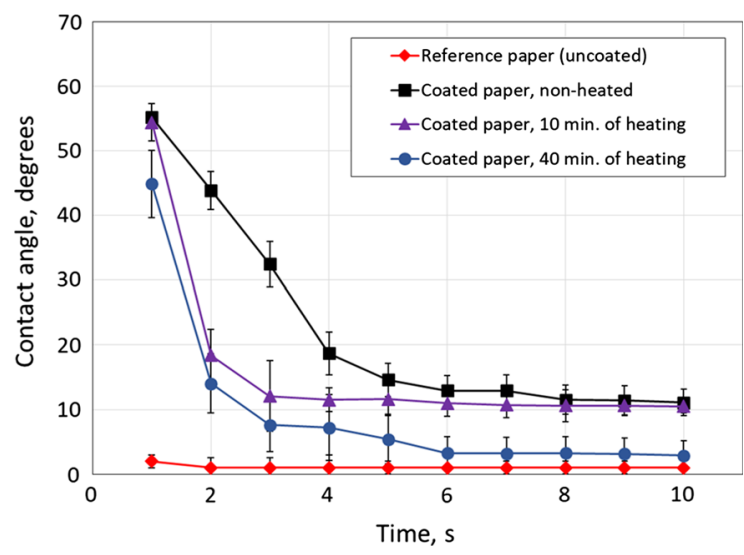

Fig. 6 Comparison of the changes in contact angle with water for uncoated (reference) paper, coated paper-immediately washed out-and coated and heated papers

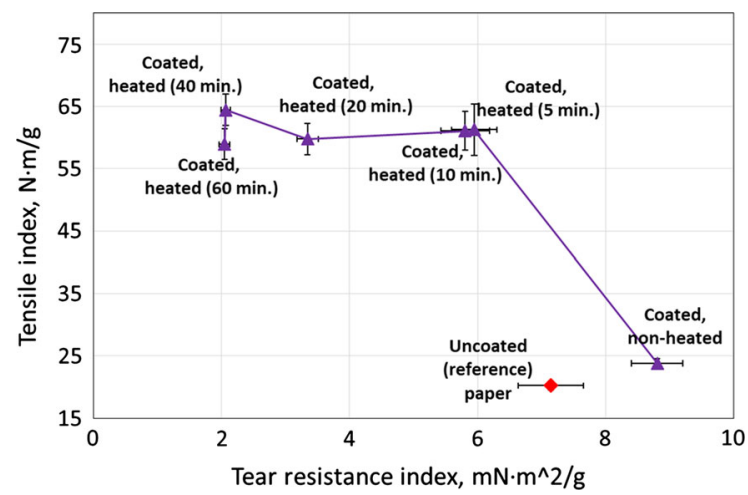

Fig. 7 Comparison of the changes of tensile index versus tear resistance index for coated papers (the value for base paper is given as a reference)

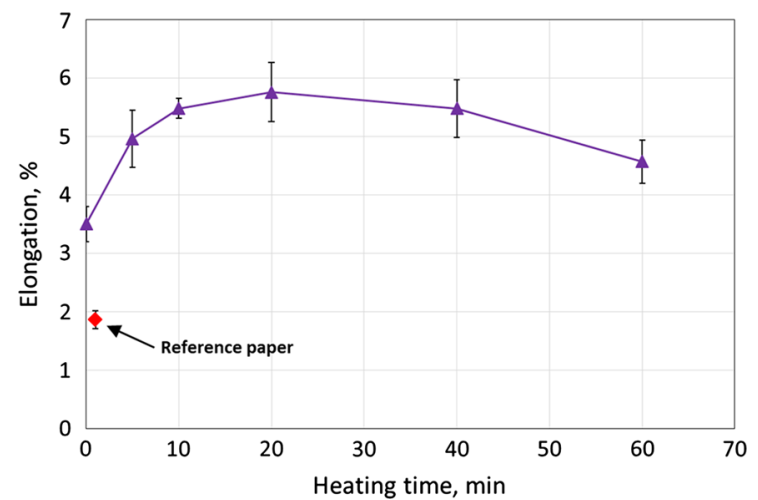

Fig. 8 Effect of heat treatment time on the elongation of coated papers (the value for base paper is given as a reference)

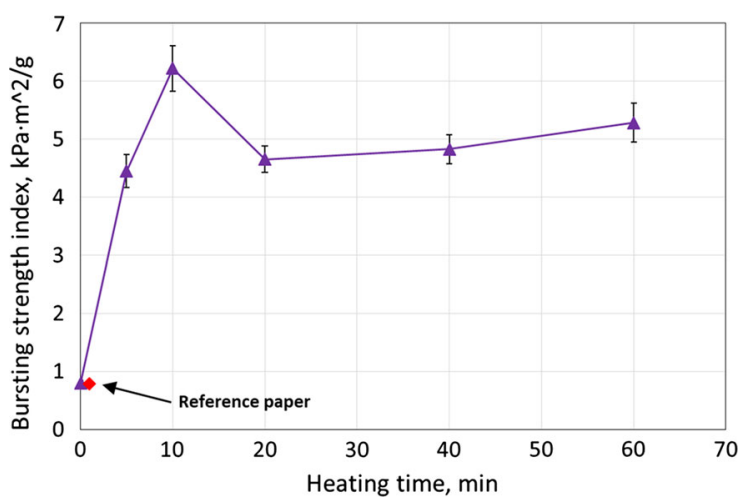

Fig. 9 Effect of heat treatment time on the bursting strength index of coated papers (the value for base paper is given as a reference) 
' 0 ' means that no heat treatment was applied (sample $\mathrm{NH}$ ), and that the solvent was removed immediately after the coating was applied. A single red rhombus point represents the value of the discussed parameter for the reference uncoated paper. The reference papers were not heated either. The data in Fig. 4 indicate that the apparent density of the studied samples of paper with a cellulose coating was higher than the apparent density of the base paper itself. In the case of the constant thickness of a coating and, thus, the same amount of deposited cellulose, it was expected that the average apparent density of the coated paper would be similar, regardless of the post-treatment method. It was revealed, however, that apparent density was increasing when heat treatment duration was prolonged.

These results could suggest that heat treatment of cellulose coating modifies the internal structure of the entire material. This is evidenced as well by the results of the measurement of air permeance (Table 1 and images presented in Fig. 5). A close view of the heattreated samples reveals the lack of continuous layer on the surface. Moreover, the fiber network is tightly surrounded by the regenerated cellulose. The lack of fibrils suggests that the small particles (e.g. fibrils, fines) could have been partially dissolved and absorbed by the cellulose-NMMO solution. This could result in higher permeance of the whole structure.

The range of changes of apparent density depended on the method of sample post-treatment. The most significant changes were already observed for short heat treatment times. After $5 \mathrm{~min}$ of heat treatment, the apparent density of the tested sample increased by approximately $0.5 \mathrm{~g} / \mathrm{cm}^{3}$, whereas change by barely $0.006 \mathrm{~g} / \mathrm{cm}^{3}$ in apparent density was observed when heating time was increased from 5 to $40 \mathrm{~min}$. Evidently, the major changes in the structure of the paper occur during the first 5-10 min of heating. Further data analysis demonstrated that the change of apparent density was caused by changes in the thickness of the samples. This implies that the increase of apparent density results from the increased shrinkage of the whole structure. A similar observation can be found in the literature (Ferreira et al. 2015).

The hydrophobic properties of applied coatings were tested for four cases: reference paper without a coating, paper with a continuous coating $(\mathrm{NH})$, and papers with a coating heated for 10 and 40 min before solvent removal. It is commonly accepted that native cellulosic fibers are mainly hydrophilic, and a paper structure is of a capillary-porous nature. The contact angle for such materials is usually equal to 0 (i.e. water immediately penetrates the paper structure if no hydrophobic additive has been used). In the case of the applied cellulose solution in NMMO, cellulose dissolution and regeneration cause the reorganisation of the intra- and inter-molecular hydrogen bonds. Other scientists (O'Sullivan 1997; Zimmermann et al. 2016) determined that conversion from cellulose I to cellulose II occurs during the cellulose regeneration process.

Furthermore, Biganska and Navard (2009) found also that the regeneration process may influence the final properties of cellulose. Cellulose regenerated in a water bath after the crystallisation of solutions exhibited a uniform and compact structure. Conversely, regeneration from the molten solution resulted in a porous structure surrounded by dense "skin". Depending on the final organisation of the structure, part of the -OH groups may not be available for interactions with liquid located at a cellulosic surface (Hubbe et al. 2015). Yamane et al. (2006) proved that regenerated cellulose can exhibit increased hydrophobic properties. The results of measurements presented in Fig. 6 demonstrated that paper without a cellulosic coating had a contact angle equal to 0 .

It was already noticed that, during the solvent removal process, the presence of cellulose coating increased the samples' resistance to water. A sample of paper without a coating, immersed in a water bath, quickly disintegrated into individual fibers. The coated samples easily survived a 2-min immersion in water, preserving their structure. This proved that the cellulose introduced into the paper bonded the fibers and made the structure more hydrophobic.

Measurements of the contact angle for a continuous regenerated cellulose coating showed an increase in the initial contact angle to more than $50^{\circ}$. This effect, however, disappeared quickly and after approximately $6 \mathrm{~s}$, the contact angle reached the constant value of circa $10^{\circ}$. The final value corresponds to the value of contact angle for micro-crystalline cellulose found in works by Yamane et al. (2006). For the sample of paper coated with cellulose and heated for $10 \mathrm{~min}$, the initial contact angle was about $50^{\circ}$ as well but it decreased more rapidly to the same value as that for continuous regenerated cellulose coating. For longer times of heat treatment (40 $\mathrm{min})$, the layer of cellulose 
was not continuous. As a consequence, the initial contact angle was lower (about $45^{\circ}$ ), and its decrease in time was faster, reaching a constant value equal to approximately $4^{\circ}$. On the basis of the measurements conducted, it can be stated that the papers with a layer of regenerated cellulose exhibited higher contact angle as compared to the samples not treated with the cellulose solution. Apparently, the observed changes might have been affected by various factors, i.e. different hydrophobicity of regenerated cellulose, surface roughness and capillary structure of the material. Therefore, full explanation is difficult and requires further investigations.

Mechanical properties of paper coated

with a cellulose solution

Tensile strength and tear resistance were measured as the key functional parameters of paper materials. The classic method of improving papermaking ability applied on an industrial scale (process of beating) causes an increase in tensile strength and, simultaneously, a decrease in tear resistance. For this, both of these parameters are often presented together. Figure 7 shows a comparison of changes in tensile strength as a function of tear resistance. A single red rhombus point represents the properties of uncoated paper. On the basis of the obtained results, it is possible to conclude that a continuous cellulose layer causes an increase in the tear resistance of paper (from 7.14 to $8.8 \mathrm{mN} \mathrm{m}^{2} / \mathrm{g}$ ), and also a small increase in tensile strength (by approximately $3.6 \mathrm{~N} \mathrm{~m} / \mathrm{g}$ ). Additional heating operation applied to coated papers resulted not only in penetration of the paper structure by the cellulose solution but also could have caused changes of the paper structure, since the hot NMMOwater system (containing about $16 \%$ of water) has an ability to swell or partially dissolve cellulose fibers. The structural changes of the samples resulted in quick and significant increase in tensile strength. Just after 5 min of heating operation, tensile strength increased by more than $40 \mathrm{~N} \mathrm{~m} / \mathrm{g}$ in comparison to uncoated, reference paper. The observed increase of the tensile strength correlated with the decreasing value of tear resistance when the heat treatment time of the coating was prolonged. These results were the basis for quantifying the optimum time of coating heat treatment as no longer than 10 min-exceeding this time resulted in excessive loss of paper tear resistance.
Interesting results were obtained while studying changes in the elongation of the samples of uncoated paper and of paper with regenerated cellulose coating (Fig. 8). The initial elongation of uncoated paper amounted to $1.86 \%$. The application of cellulose coating (without heat treatment) caused an increase in this parameter to $3.5 \%$. Heat treatment caused a further increase in elongation to approximately 5\% (after $5 \mathrm{~min}$ of heat treatment), and the maximum value was reached after $20 \mathrm{~min}$ of heating (approximately $5.8 \%$ ). Longer heat treatment times caused a decrease in this parameter. It is worth pointing out that the obtained maximum elongation was comparable with values typical of beaten cellulose pulps. An increase in both tensile strength and elongation of paper coated with cellulose indicate the high binding properties of the regenerated cellulose from the solution in NMMO. The relatively long heat treatment time (measured in minutes) required for the elongation increase was the shortcoming of the process.

Figure 9 presents the changes in bursting strength of the studied samples of paper. The results indicate that cellulose coating itself is rather weak. The bursting strength of base paper and coated paper without heat treatment was almost the same. The heat treatment applied caused a large and quick increase in bursting strength. The highest value of this parameter was obtained after $10 \mathrm{~min}$ of heat treatment, and then it decreased (up to $20 \mathrm{~min}$ ). After that time, bursting strength remained almost unchanged. These results confirm earlier observations that an increase in paper strength properties results mainly from the interactions of the regenerated cellulose with the entire matrix of the fibrous structure of paper. Longer heating times causeed the deeper penetration of a cellulosic solution into a paper structure. As a result, fibers became surrounded by a layer of cellulose, which contributes to an increased bonded area of fibrous network (this effect can be seen in photographsFig. 2c, d).

The double folds number, the only fatigue test conducted on paper, was the last property studied. This parameter is particularly important for materials exposed to multiple deformations, such as banknote paper, map paper or book cover paper. The number of double folds is frequently identified-not quite correctly-with paper fracture resistance while folded. The results obtained in this research are presented in Fig. 10. It is well known that the number of double 


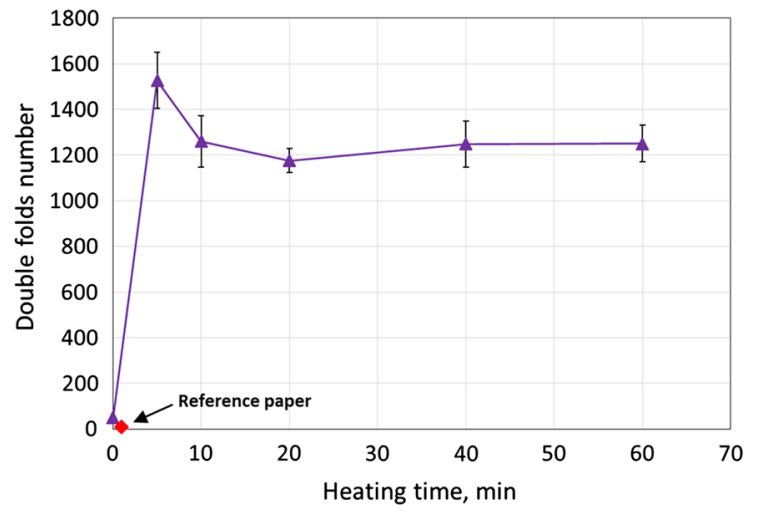

Fig. 10 Effect of heat treatment time on the double folds number of coated papers (the value for base paper is given as a reference)

folds depends mainly on the length of fibers, but also on the degree of their mutual contact area (i.e. bounded area) in the paper structure. It is also for this reason that paper made of unbeaten pulp, quickly breaks while folded. In the discussed case, the reference paper (without coating) demonstrated a number of double folds amounting to 7. Cellulose coating applied on the surface of the paper increased the value of this parameter to 37 . In turn, the relatively short heat treatment time applied (5 min) caused an increase in the number of double folds to more than 1500. Longer heating time resulted in a decrease of this parameter to the constant value of approximately 1200. This means that cellulose coating itself is not very resistant to folding. Yet again, these results indicate the significant bonding abilities of regenerated cellulose.

Considering the changes in strength properties of all coated papers it can be concluded that the highest values of these properties were found when coated papers were subjected to heat treatment for about 5-10 min. Longer treatment caused decrease in these properties. This allows the argument that this negative effect could be caused by exceedingly long NMMOfibrous material interactions at high temperatures, which may have resulted in the excessive dissolution of fiber structural elements (e.g. cellulose, hemicellulose) within the paper. Consequently, it could have led to partial damage of the fibrous network and overall loss in material mechanical strength. This effect will be further investigated.

\section{Conclusion}

On the basis of the conducted research, it can be concluded that it is possible to use regenerated cellulose from an $\mathrm{N}$-Methylmorpholine $\mathrm{N}$-oxide solution to coat paper materials. The obtained results showed that regenerated cellulose-based coatings changed the surface, structural and strength characteristics of paper. Additional heat treatment enabled the modification of those properties even more significantly. Heat treatment proved to be most effective in terms of strength properties improvement when applied for 5-10 min. Coated papers subjected to that optimal "thermal conditioning" exhibited an increase in tensile index, elongation, bursting strength index and double folds number. It is believed that heat treatment enhanced the penetration of the NMMO cellulose solution into the paper structure resulting in the higher number of contacts between paper fibers and regenerated cellulose chains. Therefore, the bonded area within the fibrous matrix was increased, which reinforced the coated papers. When heat treatment was not applied, penetration of the coating solution into the paper structure was limited and, thus, regenerated cellulose interacted mostly with surface fibers, covering them with a continuous coating film. As a result, additional bonding did not form deep inside the paper fiber network and the internal structure of the material was not mechanically strengthened. Such surface modification, however, contributed to the highest smoothness and hydrophobicity out of all the examined papers. The measurements of the contact angle for continuous regenerated cellulose coating showed an initial contact angle of about $50^{\circ}$. This value, however, decreased quickly and, after approximately $6 \mathrm{~s}$, the contact angle reached the constant value of about $10^{\circ}$, which corresponds to the value of contact angle for micro-crystalline cellulose. In general, the contact angle decreased as heat treatment time increased. It should be mentioned that the necessity of subjecting a coated paper to the process of solvent removal stage (washing out) is a shortcoming of this method, which limits its wet-end applications in the classical process of paper production. An increase in strength properties, however, and also (as previously reported in the literature-Yoon 2007) the possible use of various substances as additives to such coating solutions, may lead to the development of innovative products. As a result, the 
presented method may be beneficial for the production of specialty materials for which quality and specific properties play a decisive role in relation to the efficiency of the production process and also to the price of the final product.

Open Access This article is distributed under the terms of the Creative Commons Attribution 4.0 International License (http:// creativecommons.org/licenses/by/4.0/), which permits unrestricted use, distribution, and reproduction in any medium, provided you give appropriate credit to the original author(s) and the source, provide a link to the Creative Commons license, and indicate if changes were made.

\section{References}

Alves L, Medronho B, Antunes FE, Romano A, Miguel GM, Lindman B (2015) On the role of hydrophobic interactions in cellulose dissolution andregeneration: colloidal aggregates and molecular solutions. Colloids Surf A Physicochem Eng Asp 483:257-263

Alves L, Medronho B, Antunes FE, Topgaard D, Lindman B (2016) Dissolution state of cellulose in aqueous systems. 1. Alkaline solvents. Cellulose 23:247-258

Andersson C (2008) New ways to enhance the functionality of paperboard by surface treatment-a review. Packag Technol Sci 21:339-373

Biermann O, Hadicke E, Koltzenburg S, Muller-Plathe F (2001) Hydrophilicity and lipophilicity of cellulose crystal surfaces. Angew Chem Int Ed 40(20):3822-3825

Biganska O, Navard P (2009) Morphology of cellulose objects regenerated from cellulose- $N$-methylmorpholine $N$-oxidewater solutions. Cellulose 6:179-188

Cao NJ, Xu Q, Chen CS, Gong CS, Chen LF (1994) Cellulose hydrolysis using zinc-chloride as a solvent and catalyst. Appl Biochem Biotechnol 45(6):521-530

Chen JH, Guan Y, Wang K, Xu F, Sun RC (2015) Regulating effect of hemicelluloses on the preparation and properties of composite Lyocell fibers. Cellulose 22(3):1505-1516

Choi JO, Jitsunari F, Asakawa F, Park HJ, Lee DS (2002) Migration of surrogate contaminants in paper and paperboard into water through polyethylene coating layer. Food Addit Contam 19(12):1200-1206

Dufresne A (2012) Nanocellulose: from nature to high performance tailored materials. Walter De Gruyter Gmbh, Berlin. ISBN 9783110254563

Dufresne A (2013) Nanocellulose: a new ageless bionanomaterial. Mater Today 16:220-227. https://doi.org/10.1016/j. mattod.2013.06.004

Erdman A, Kulpinski P, Olejnik K (2016) Application of nanocomposite cellulose fibers with luminescent properties to paper functionalization. Cellulose 23(3):2087-2097

Fall AB, Burman A, Wågberg L (2014) Cellulosic nanofibrils from eucalyptus, acacia and pine fibers. Nordic Pulp Pap Res J 29(1):129-143

Ferreira SE, Lanzoni ME, Costa CAR, Deneke C, Bernardes JS, Galembeck F (2015) Adhesive and reinforcing properties od soluble cellulose: a repulpable adhesive for wet and dry cellulosic substrates. ACS Appl Mater Interfaces 7:18750-18758

Ferrer A, Quintana E, Filpponen I, Solala I, Vidal T, Rodriuez A, Laine J, Rojas O (2012) Effect of residual lignin and heteropolysaccharides in nanofibrillar cellulose and nanopaper from wood fibers. Cellulose 19(6):2179-2193

Fukuzumi H, Saito T, Iwata T, Kumamoto Y, Isogai A (2009) Transparent and high gas barrier films of cellulose nanofibers prepared by TEMPO-mediated oxidation. Biomacromol 10(1):162-170

Gällstedt M, Brottman A, Hedenqvist MS (2005) Packaging related properties of protein- and chitosan-coated paper. Packag Technol Sci 18(4):161-170

Garcia MA, Martino MN, Zartizky NE (1999) Edible starch films and coating char-acterization: scanning electron microscopy, water vapor transmission and gas permeabilities. Scanning 21(5):358-420

Gardner DJ, Oporto GS, Mills R, Samir MASA (2008) Adhesion and surface issues in cellulose and nanocellulose. J Adhes Sci Technol 22:545-567

Hansen N, Plackett D (2008) Sustainable films and coatings from hemicelluloses: a review. Biomacromol 9:1493-1505

Henriksson M, Berglund LA, Isaksson P, Lindström T, Nishino $\mathrm{T}$ (2008) Cellulose nanopaper structures of high toughness. Biomacromol 9(6):1579-1587

Hubbe MA, Gardner DJ, Shen W (2015) Contact angles and wettability of cellulosic surfaces: a review of proposed mechanisms and test strategies. BioResources 10(4):8657-8749

Hubbe MA, Ferrer A, Tyagi P, Yin Y, Salas C, Pal L, Rojas OJ (2017) Nanocellulose in thin films. coatings and plies for packaging applications: a review. BioResources 12(1):2143-2333

Hult E-L, Ropponen J, Poppius-Levlin K, Ohra-Aho T, Tamminen $\mathrm{T}$ (2013) Enhancing the barrier properties of paper board by a novel lignin coating. Ind Crops Prod 50:694-700

Jie XM, Cao YM, Qin JJ, Liu JH, Yuan Q (2005) Influence of drying method on morphology and properties of asymmetric cellulose hollow fiber membrane. J Membr Sci 246(2):157-165

Johnson DL (1969) Process for strengthening swellable fibrous material with an amine oxide and the resulting material. US Patent 3447956

Kalashnikova I, Bizot H, Cathala B, Capron I (2012) Modulation of cellulose nanocrystals amphiphilic properties to stabilize oil/water interface. Biomacromol 13:267-275

Kangas H, Lahtinen P, Sneck A, Saariaho AM, Laitinen O, Hellén E (2014) Characterization of fibrillated celluloses. A short review and evaluation of characteristics with a combination of methods. Nordic Pulp Pap Res J 29(1):129-143

Khwaldia K, Arab-Tehrany E, Desobry S (2010) Biopolymer coatings on paper packaging materials. Compr Rev Food Sci Food Saf 9(1):82-91

Kosan B, Michels Ch, Meister F (2008) Dissolution and forming of cellulose with ionic liquids. Cellulose 15(1):59-66

Kulpinski P (2007) Cellulose fibers modified by hydrophobic type polymer. J Appl Polym Sci 104:398-409 
Kulpinski P, Smiechowicz E, Niekraszewicz B, Baciarelli A (2011) Cellulose fibers modified with silver nanoparticles. Cellulose 18:975-985

Lavoine N, Desloges I, Dufresne A, Bras J (2012) Microfibrillated cellulose-its barrier properties and applications in cellulosic materials: a review. Carbohydr Polym 90:735-746

Lavoine N, Desloges I, Khelifi B, Bras J (2014) Impact of different coating processes of microfibrillated cellulose on the mechanical and barrier properties of paper. J Mater Sci 49:2879-2893

Lee SY, Mohan DJ, Kang IA, Doh GH, Lee S, Han SO (2009) Nanocellulose reinforced PVA composite films: effects of acid treatment and filler loading. Fibers Polym 10:77-82

Lindman B, Karlstrom G, Stigsson L (2010) On the mechanism of dissolution of cellulose. J Mol Liq 156:76-81

Liu A, Walther A, Ikkala O, Belova L, Berglund LA (2011) Clay nanopaper with tough cellulose nanofiber matrix for fire retardancy and gas barrier functions. Biomacromol 12:633-641

Mazeau K (2011) On the external morphology of native cellulose microfibrils. Carbohyd Polym 84:524-532

Medronho B, Lindman B (2014) Competing forces during cellulose dissolution: from solvents to mechanisms. Curr Opin Colloid Interface Sci 19:32-40

Medronho B, Lindman B (2015) Brief overview on cellulose dissolution/regeneration interactions and mechanisms. Adv Coll Interface Sci 222:502-508

Medronho B, Romano A, Graca Miguel M, Stigsson L, Lindman B (2012) Rationalizing cellulose (in)solubility: reviewing basic physicochemical aspects and role of hydrophobic interactions. Cellulose 19:581-587. https://doi.org/10. 1007/s10570-011-9644-6

Melville AJ, Topping DJ, Willis DP (2014) Bearing components and processes for depositing additives, especially fluoropolymers, on cellulose. US 8703668 B2

Mngomezulu ME, John MJ (2017) Thermoset cellulose nanocomposites: flammability characteristics. In: Kargarzadeh H, Ahmad I, Sabu T, Alain Dufresne A (eds) Handbook of nanocellulose and cellulose nanocomposites. p 263, ISBN: 978-3-527-68999-6

Nakagaito AN, Yano H (2005) Novel high-strength biocomposites based on microfibrillated cellulose having nanoorder-unit web-like network structure. Appl Phys A 80:155-159

O'Sullivan A (1997) Cellulose: the structure slowly unravels. Cellulose 4:173-207

Peresin M, Rojas OJ (2014) Electrospinning of nanocellulosebased materials. In: Oksman K, Bismarck A, Rojas OJ, Sain M (eds) Handbook of green materials. Part 3: self- and direct-assembling of bionanomaterials, Chapter 10. World Scientific Publishing, Singapore, pp 163-183. ISBN 9789814566452
Rhim J-W, Lee J-H, Hong S-I (2006) Water resistance and mechanical properties of biopolymer (alginate and soy protein) coated paperboards. LWT Food Sci Technol 39(7):806-813

Rosenau T, Potthast A, Sixta H, Kosma P (2001) The chemistry of side reactions and byproduct formation in the system NMMO/cellulose (Lyocell process). Prog Polym Sci 26:1763-1837

Salas C, Nypelö T, Abreu CR, Carrillo C, Rojas OJ (2014) Nanocellulose properties and applications in colloids and interfaces. Curr Opin Colloid Interface Sci 19:383-396

Savadekar NR, Karande VS, Vigneshwaran N, Kadam PG, Mhaske ST (2015) Preparation of cotton linter nanowhiskers by high-pressure homogenization process and its application in thermoplastic starch. Appl Nanosci 5:281-290. https://doi.org/10.1007/s13204-014-0316-3

Siró I, Plackett D (2010) Microfibrillated cellulose and new nanocomposite materials: a review. Cellulose 17:459-467

Spence KL, Venditti RA, Rojas OJ, Habibi Y, Pavlak JJ (2010) The effect of chemical composition on microfibrillar cellulose films from wood pulps: water interactions and physical properties for packaging applications. Cellulose 17:835-844

Šturcová A, Davies GR, Eichhorn SJ (2005) Elastic modulus and stress-transfer properties of tunicate cellulose whiskers. Biomacromol 6:1055-1061

Tingaut P, Eyholzer C, Zimmermann T (2011) Functional polymer nanocomposite materials from microfibrillated cellulose. In: Hashim A (ed) Advances in nanocomposite technology. InTech. https://doi.org/10.5772/20817

Tracton AA (ed) (2007) Coatings technology. Fundamentals, testing and processing techniques. CRC Press, Taylor \& Francis Group, London, New York. ISBN 978-1-42004406-5

Yamane C, Aoyagi T, Ago M, Sato K, Okajima K, Takahashi T (2006) Two different surface properties of regenerated cellulose due to structural anisotropy. Polym J 38(8):819-826

Yoon S-Y (2007). Bonding material coated clay for improving paper properties. Doctoral dissertation. Georgia Institute of Technology, USA

Zimmermann T, Pöhler E, Schwaller P (2005) Mechanical and morphological properties of cellulose fibril reinforced nanocomposites. Adv Eng Mater 7:1156-1161

Zimmermann T, Bordeanu N, Strub E (2010) Properties of nanofibrillated cellulose from different raw materials and its reinforcement potential. Carbohydr Polym 79:1086-1093

Zimmermann R, Muller Y, Freudenberg U, Jehnichen D, Potthast A, Rosenau T, Werner C (2016) Oxidation and structural changes in NMMO-regenerated cellulose films. Cellulose 23(6):3535-3541 